\section{Zu lange Bettzeit}

Helga Peter

Marburg, Deutschland

\section{Synonyme}

Exzessive Bettzeit

\section{Englischer Begriff}

excessive time in bed

\section{Definition}

Die Betroffenen verbringen in der Nachtphase regelmäßig exzessiv lange Zeit im Bett. Sie haben lange Schlaflatenzen oder ausgedehnte Wachliegezeiten während der Nacht, fühlen sich aber dadurch nicht gestört. Sie äußern keine Insomniebeschwerden und sind tagsüber nicht beeinträchtigt.

Die $>$,ICSD-3“ ordnet die Störung bei $>$ „Insomnie“ unter Isolierte Symptome und Normvarianten ein. 